\section{Screening Brassica Cultivars for Resistance to Western Oregon Clubroot Pathotypes}

\author{
Aaron Heinrich ${ }^{1,3}$, Shinji $\mathrm{Kawai}^{2}$, and Jim Myers ${ }^{2}$
}

AdDITIONAL INDEX wORDs. Plasmodiophora brassicae, clubroot management, host resistance, European clubroot differential set

SUMMARY. Growing resistant cultivars from the Brassicaceae family (brassicas) is an effective strategy to minimize crop loss caused by the soilborne pathogen Plasmodiophora brassicae (clubroot). However, there are many clubroot pathotypes, and genetic resistance to clubroot may be pathotype-specific. To determine which pathotypes are present in western Oregon, diseased roots were collected from five farms and identified by the European clubroot differential (ECD) set. To assess resistance to the identified pathotypes, 21 vegetable cultivars from nine crops with purported resistance to clubroot were evaluated for disease incidence and severity in field and greenhouse studies. The crops evaluated included broccoli (Brassica olevacea var. italica), cauliflower (B. olevacea var. botrytis), brussels sprouts (B. olevacea var. gemmifera), cabbage (B. olevacea var. capitata), napa cabbage (Brassica rapa var. pekinensis), pak choi (B. rapa var. chinensis), kohlrabi (B. olevacea var. gongylodes), turnip (B. rapa var. rapa), and rutabaga (Brassica napus var. napobrassica). ECD host reaction showed similar virulence among clubroot collections, and all field isolates had the same ECD pathotype designation, 16/02/ 30. Compared with a crop-specific susceptible control, 17 of 21 cultivars had some resistance to clubroot, and of those, 15 were highly resistant ( $\leq 15 \%$ incidence with low disease severity). This research demonstrated that western Oregon farmers have several commercially available cultivars with resistance to the dominant pathotyope in the region. However, each farmer must evaluate the suitability of these cultivars to meet consumer and industry requirements.

$\mathrm{T}$ The soilborne pathogen clubroot is a significant pest of brassica crop-producing regions worldwide (Dixon 2006, 2009). The pathogen causes root swelling (galls or clubs) that disrupt the vascular tissue, and impair water and nutrient uptake. Infected plants may be stunted, wilt even when soil moisture is adequate, appear discolored, or when severe, die. This can result in significant economic loss because of reduced crop yield and product quality (Dixon, 2009; Strelkov et al., 2005).

Eradicating the clubroot pathogen from an infested field is unlikely

This publication was made possible by grants from the Western Sustainable Agriculture Research and Education Program and the Agricultural Research Foundation.

We would like to thank Ryan Miller and Andrew Donaldson for their help with lab and fieldwork as well as the companies Bejo Seeds Inc. and Osborne Seeds for supplying us with the cultivars evaluated in this study.

${ }^{1}$ Department of Horticulture, Oregon State University, North Willamette Research and Extension Center, 15210 NE Miley Road, Aurora, OR 97002

${ }^{2}$ Department of Horticulture, Oregon State University, 4017 Agricultural and Life Sciences Building, Corvallis, OR 97331

${ }^{3}$ Corresponding author. E-mail: Aaron.Heinrich@ oregonstate.edu.

doi: 10.21273/HORTTECH03694-17 because clubroot produces thick-walled resting spores, some of which may remain viable for 17 years or more in the absence of a host (Wallenhammar, 1996). However, most spores die off quickly. Wallenhammar (1996) estimated the half-life of clubroot spores to be $\approx 4$ years, although recent work suggests that the half-life may be less (Peng et al., 2015). Because there is a direct relationship between spore concentration and disease severity (Hwang et al., 2011; Tsushima et al., 2010), a long enough rotation out of brassicas can reduce disease severity and economic loss. However, predicting rotation lengths that will minimize crop loss is difficult because of the complex interactions among spore concentration, soil physical and chemical properties, and environmental conditions on disease development (Gossen et al., 2014). In heavily infested fields, rotations out of brassicas for a minimum of 5 years may be required to minimize economic losses (Peng et al., 2015).

Clubroot is a problem for Oregon farmers. In 2012, a group of 37 conventional and organic vegetable growers who grow brassicas were surveyed about their experience with clubroot. Of the 19 who responded, all indicated that clubroot was an important issue, with $58 \%$ saying that it was very important (unpublished data). Many smaller-acreage diversified vegetable farms do not have sufficient acreage to implement a rotation out of brassicas of 5 years or more that is necessary to reduce clubroot severity. Nor do they have rotational crops as profitable as brassicas. Clubroot has had less economic impact on larger farms in Oregon that grow brassicas for processing. Larger farms often have more crop rotation options, and they can avoid infested fields by moving brassica production to uninfected leased fields.

A large body of research has explored strategies to minimize crop loss from clubroot. This work has been compiled in multiple review papers (Donald and Porter, 2009; Hwang et al., 2014). As discussed in these review papers, many strategies are not consistently effective, do not provide sufficient disease suppression, require changes to farming practices, are too expensive, or are not permitted by organic certifiers. Of all the management strategies studied, growing resistant cultivars is an attractive option. Resistant cultivars require no change in farming practices or equipment, provide greater flexibility as to when and where to plant, and may be far less expensive than other options. Furthermore, resistant cultivars produce far fewer clubs than susceptible cultivars (Adhikari et al., 2012; Saude et al., 2012; Sharma et al., 2013), which reduces the number of spores being added to the soil compared with susceptible cultivars (Hwang et al.,

\begin{tabular}{llll}
\hline $\begin{array}{l}\text { Units } \\
\text { To convert U.S. to SI, } \\
\text { multiply by }\end{array}$ & U.S. unit & SI unit & $\begin{array}{l}\text { To convert SI to U.S., } \\
\text { multiply by }\end{array}$ \\
\hline 29.5735 & $\mathrm{fl} \mathrm{oz}$ & $\mathrm{mL}$ & 0.0338 \\
0.3048 & $\mathrm{ft}$ & $\mathrm{m}$ & 3.2808 \\
3.7854 & gal & $\mathrm{L}$ & 0.2642 \\
2.54 & inch $(\mathrm{es})$ & $\mathrm{cm}$ & 0.3937 \\
14.7868 & tablespoon $(\mathrm{s})$ & $\mathrm{mL}$ & 0.0676 \\
$\left({ }^{\circ} \mathrm{F}-32\right) \div 1.8$ & ${ }^{\circ} \mathrm{F}$ & ${ }^{\circ} \mathrm{C}$ & $\left({ }^{\circ} \mathrm{C} \times 1.8\right)+32$
\end{tabular}


2012). Thus, resistant cultivars have the potential to reduce future disease incidence and severity.

Brassica vegetable crops have been developed with durable resistance to clubroot, and seed companies have released clubroot-resistant cultivars of broccoli, cauliflower, cabbage, brussels sprouts, and napa cabbage (Diederichsen et al., 2009; Piao et al., 2009). In field and greenhouse trials (Adhikari et al., 2012; Saude et al., 2012; Sharma et al., 2013) cultivars have been evaluated for resistance to pathotypes $2,3,5$, and 6 as designated by the Willimans clubroot differential set (Williams, 1966), but not to pathotype 7 , which has been identified as predominant on the west coast of the United States (Dobson et al., 1983). The resistance genes that have been incorporated into brassica crops may not be effective against all clubroot pathotypes (Diederichsen et al., 2009). Therefore, it is important that cultivars with purported clubroot resistance are evaluated against the pathotypes present in each brassica production region.

The goal of this research was to provide farmers with information about brassica cultivars that have demonstrated resistance to the clubroot pathotypes present in western Oregon. To meet this goal, we had two objectives: 1) to identify the pathotypes present in western Oregon using the ECD set (Warwick Crop Center, University of Warwick Wellesbourne, United Kindom), and 2) to evaluate clubroot resistance of commercially available cultivars with purported resistance to the dominant pathotypes identified by the ECD set.

\section{Materials and methods}

Pathotype Determination USING THE ECD SET. Clubroot galls were collected from a single infected plant from each of five locations in Oregon's Willamette Valley in 2015 and frozen for no longer than 7 months. A clubroot spore suspension was created by cleaning galls to remove soil, macerating with distilled water in a blender, filtering the suspension through several layers of cheesecloth to remove plant material, and quantifying the spore concentration using a hemocytometer. The suspension was then diluted to $10^{7}$ spores $/ \mathrm{mL}$ and refrigerated for up to 1 week before use.

Each clubroot collection was screened against the 15 differential hosts of the ECD set (Table 1). Plants were grown in cone tubes (1.5 inch diameter $\times 5.5$ inches deep) containing a $3: 1(\mathrm{v} / \mathrm{v})$ potting mix: loam soil with a $\mathrm{pH}$ of 5.5 . Twenty-eight cone

Table 1. European clubroot differential (ECD) series host species and binary values used to identify clubroot pathotypes in western Oregon (Buczacki et al., 1975).

\begin{tabular}{llr}
\hline ECD no. & \multicolumn{1}{c}{ Differential host } \\
\hline Brassica rapa & Binary value \\
1 & var. rapifera line aaBBCC fodder turnip & \\
2 & var. rapifera line AAbbCC fodder turnip & 2 \\
3 & var. rapifera line AABBcc fodder turnip & 2 \\
4 & var. rapifera line AABBCC fodder turnip & 8 \\
5 & var. pekinensis 'Granaat' & 16 \\
Brassica napus & & \\
6 & var. napus 'Nevin' & 1 \\
7 & var. napus 'Giant Rape' & 2 \\
8 & var. napus selection of 'Giant Rape' & 4 \\
9 & var. napus New Zealand clubroot resistant rape & 8 \\
10 & var. napobrassica 'Wilhemsburger'y & 16 \\
Brassica oleracea & & \\
11 & var. capitata 'Badger Shipper'y & 1 \\
12 & var. capitata 'Bindsachsener' & 2 \\
13 & var. capitata 'Jersey Queen'y & 4 \\
14 & var. capitata 'Septa' & 8 \\
15 & var. acephala 'Verheul' & 16 \\
\hline
\end{tabular}

${ }^{\mathrm{z}} \mathrm{aaBBCC}, \mathrm{AAbbCC}, \mathrm{AABBcc}$, and AABBCC refer to the allelic state of a set of three resistance genes present in differential lines of turnip developed by Wit (1964). Lower case indicates susceptibility and upper case letters indicates resistance to corresponding races of clubroot.

${ }^{y^{2}}$ This cultivar is part of the Williams clubroot differential set (Williams, 1966). tubes per ECD host were seeded in early Spring 2016. One milliliter of spore suspension was pipetted into each planting hole before covering the seed. Plants were grown with natural light in the greenhouse with night to daytime temperature fluctuations between 60 and $80{ }^{\circ} \mathrm{F}$. The average media temperature in the pots during the study was $67^{\circ} \mathrm{F}$. The plants were watered twice daily to keep pots moist, and were fertilized weekly with one tablespoon of $24 \mathrm{~N}-3.5 \mathrm{P}-14 \mathrm{~K}$ per gallon of water. The plants of each cultivar were grown together and not randomized in the greenhouse; however, trays were frequently rotated to eliminate variability associated with the distribution of the irrigation system.

Five weeks after planting, potting media was washed from the roots, and roots were evaluated for clubroot incidence and severity. Root disease severity was rated on the following scale: $0=$ no visible clubbing, $1=$ small clubs on lateral roots, $2=<50 \%$ of main root system clubbed, and $3=>50 \%$ of main root system clubbed. Disease severity index (DSI) was calculated as:

$$
\frac{(R 1 \times 2+R 2 \times 3+R 3 \times 5)}{5}
$$

where $R 1, R 2$, and $R 3$ are the total percentages of plants evaluated with a rating of 1,2 , and 3 , respectively (Dixon and Robinson, 1986). Using this index, each ECD host was assigned to a reaction type as resistant (DSI $=0$, designated “-”), uncertain $(0<\mathrm{DSI}<33$, designated "?"), or susceptible (DSI > 33 designated “+”). Each collection was then assigned a numeric code based on each ECD host reaction as described by Buczacki et al. (1975). All uncertain reactions ("?)") were regarded as resistant for purposes of calculating virulence designations.

Cultivar SCREENING FOR Clubroot resistance. Twenty-one commercially available brassica cultivars from nine brassica crops with purported clubroot resistance were screened in field and greenhouse trials. Resistance could have been stated by seed companies, seed distributors, or based on farmer experience. The crops evaluated included broccoli, cauliflower, brussels sprouts, cabbage, napa cabbage, pak choi, kohlrabi, turnip, 
and rutabaga. For each crop, a clubroot susceptible cultivar was planted as a comparison. In 2015, five on-farm trials were initiated in fields with a history of clubroot in collaboration with conventional and organic fresh market vegetable growers. However, the disease was only uniformly distributed across field plots at two sites. Only the results from these two trials are discussed here. Because some farms were organically certified, some cultivars with treated seed could not be screened in the field; however, they were screened in the greenhouse.

Field site 1 was conducted on a loam soil with a $\mathrm{pH}$ of 6.2 on an organic farm on Sauvie Island outside of Portland, OR. This field had experienced a complete crop failure on broccoli in 2013 because of clubroot. On 29 Apr. 2015, the cultivars were transplanted in two rows per 36-inch bed with 11 -inch in-row spacing. Each plot was 10-ft-long and randomized in a complete block design with six replicates. The field was irrigated with overhead sprinklers. Seven to nine plants per plot were carefully excavated to minimize loss of lateral clubs. Because of different maturity dates, roots of cabbage, broccoli, and all other crops were evaluated at 93 , 61 , and $52 \mathrm{~d}$ after transplanting, respectively, for disease incidence and severity [Eq. (1)].

Field site 2 , was also located on Sauvie Island outside of Portland, $\mathrm{OR}$, on a conventional farm growing cabbage for processing. Three green cabbage cultivars (Kilaton, Tekila, and Kilagreg) and one red cabbage (Lodero) were direct-seeded in 230-ft-long unreplicated strips. A single row of each cultivar was planted side by side with 30 -inch row spacing on 24 June 2015. The strips allowed us to locate part of the field with uniform clubroot infestation for our evaluations. The cultivar planted by the grower, Gazelle, was used as a susceptible control. The soil at field site 2 was a silt loam with a $\mathrm{pH}$ 6.3. The crop was watered with overhead sprinklers. On 15 July, plants were thinned to an inrow spacing of 12 inches. On 30 Sept., a 100 -ft section of the experimental area was identified as having uniform, high incidence, and severity. This was assessed by evaluating roots of the susceptible cultivar on either side of the resistant cultivars. In this $100-\mathrm{ft}$ section, five random strips perpendicular to the rows were chosen, and five consecutive plants were excavated for evaluation from each cultivar across each sampling strip for a total of 25 plants of each cultivar. Roots were evaluated for disease incidence and severity.

All cultivars were evaluated in the greenhouse. A spore suspension of $10^{7}$ spores $/ \mathrm{mL}$ was created by the methods previously given. The suspension contained spores from each of the five sites that were used in the ECD set. Equal weights of root from each clubroot collection were added and macerated. Using the same cone tubes and growing media given previously, $\mathrm{l} \mathrm{mL}$ of spore suspension was pipetted into each planting hole at seeding. A total of 28 cone tubes were seeded for each cultivar, and a susceptible control for each crop was grown out. Five weeks after planting, roots were washed and evaluated for clubroot incidence and disease severity using the methods previously given.
For the replicated study (field site 1), disease incidence and DSI for each crop were subjected to analysis of variance in SAS using the PROC GLM procedure (version 9.3; SAS Institute, Cary, NC). Mean separation was determined using Tukey's test $(P=0.05)$.

\section{Results and discussion}

Clubroot incidence (CI) and DSI of ECD set hosts are given in Table 2. Virulence and reaction were relatively uniform for the five field isolates. No visual clubbing was observed for ECD hosts $1-4,8$, and 10 , and a low CI was observed for all clubroot collections for ECD 6. All clubroot collections had the same ECD numerical pathotype designation, 16/02/30 (Table 3 ).

Three of the four hosts in the ECD set are also part of the Williams differential set. These include ECD 10,11 , and 13 ('Wilhelmsburger', 'Badger Shipper', and 'Jersey Queen', respectively). The ECD pathotype identified in this study $(16 / 02 / 30)$ would correspond to either pathotype 3 or 6 using the Williams set. The ECD pathotype identified in this study has not been identified in Canada or the eastern U.S. (Strelkov et al., 2005, 2006, 2016). An evaluation of 13 clubroot collections from the west coast of the United States identified the presence of pathotypes $16 / 02 / 31$ and $16 / 03 / 31$, which the authors designated as pathotype 7 (Dobson et al., 1983). Williams (1966) also identified pathotype 7 from a single sample from California. For a collection to be designated as pathotype 7 , a positive reaction for ECD 11 ('Badger Shipper') is required.

Table 2. Clubroot incidence (CI) and disease severity index (DSI) of European clubroot differential (ECD) set hosts to clubroot collections from western Oregon.

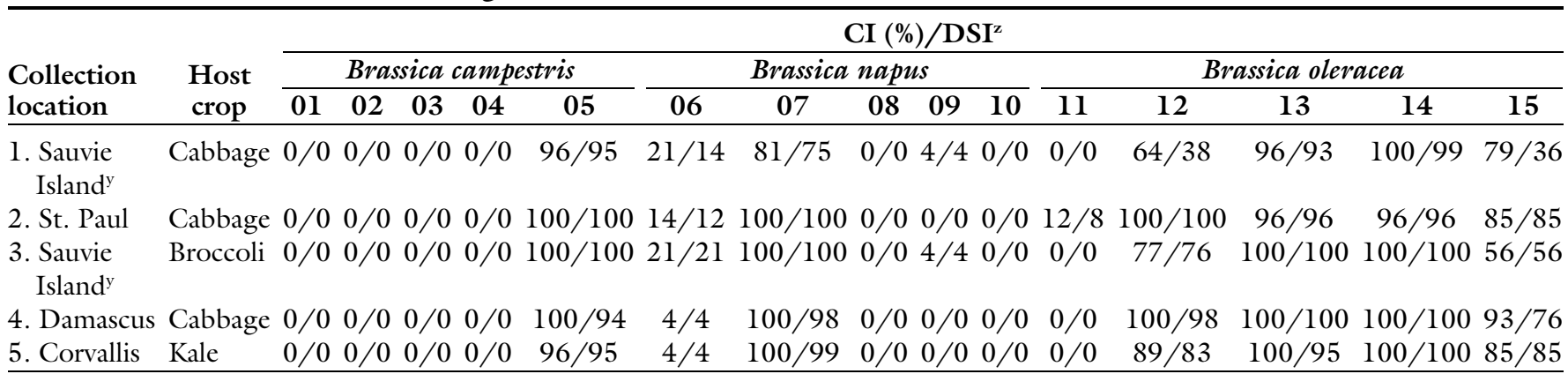

${ }^{\mathrm{z}} \mathrm{CI}=$ percentage of total plants evaluated with visible clubbing; DSI $=(R 1 \times 2+R 2 \times 3+R 3 \times 5) \div 5$, where $R 1, R 2$, and $R 3$ are the percentages of total plants evaluated with a rating of 1 (small clubs on lateral roots), 2 ( $<50 \%$ of main root system clubbed), and 3 ( $>50 \%$ of main root system clubbed), respectively.

${ }^{y}$ This collection location was also the location of a field trial (Table 4$)$. 
This was not observed in our study; however, one collection had a low incidence (Table 2 ) and was given the uncertain designation "?”.

Clubroot differential sets have their limitations and results must be interpreted carefully. Within field populations, there is a mixture of virulent pathotypes (Crute et al., 1980) and the differential sets may only identify the dominant pathotype. For example, when single spore isolates were taken from field populations, Xue et al. (2008) identified multiple pathotypes within a population. Different pathotypes can even be found inside a single club (Jones et al., 1982). Some pathotypes occur at a very low frequency and infect only a few plants of a susceptible differential host, resulting in an uncertain reaction. This may be what occurred for collections from sites 1,2 , and 3 that showed low disease incidence for ECD 9 and 11 (Table 2). To amplify the frequency of less dominant pathotypes, Dobson et al. (1983) recommends collecting clubbed roots for a differential host that had an uncertain reaction $(\mathrm{DSI}<33)$ and using the clubs to reinoculate the differential host.

Another possibility for low disease incidence for a differential host may be due to genetic diversity within a host differential (Kuginuki et al., 1999). Most Brassica species are outcrossing which is enforced by a sporophytic self-incompatibility system [the primary exception being $B$. napus (canola) which is not part of the ECD differential set]. Outcrossing species are genetically heterogeneous with each individual potentially varying for clubroot resistance alleles. Because of inbreeding depression, it is difficult if not impossible to produce inbreds with a uniform genotype for resistance. In some cases, resistance is quantitative with more than one gene involved, and some loci may still be segregating.

CI and DSI for cultivars with purported resistance and for susceptible cultivars are given in Table 4 . At field site 1, high disease pressure was uniformly distributed across the field site, and the CI and DSI for all cropspecific susceptible cultivars were $\geq 88 \%$ and $\geq 69 \%$, respectively, except in the case of rutabaga. None of the resistant cultivars were completely resistant to clubroot; however, CI and DSI were significantly less than the susceptible control for most crops. For example, at field site 1, $100 \%$ of plants of susceptible cabbage, 'Farao', had visible clubbing compared with $\leq 5 \%$ of the resistant cabbage cultivars Kilaton, Kilagreg, and Lodero.

Field site 2 also had uniform disease pressure and severity across the designated sampling area; however, this trial was not randomized and consisted of unreplicated strips through the field from which subsamples were collected and evaluated. The CI for the susceptible cabbage cultivar Gazelle was 100\% compared with $\leq 15 \%$ for the resistant cultivars. No visible clubroot symptoms were observed for the green cabbage cultivar Tekila.
In the greenhouse study, almost all susceptible cultivars had $100 \% \mathrm{CI}$, all with the highest disease rating $\{R\}$ [Eq. (1)]\}, whereas most resistant cultivars showed no visible symptoms. Conditions in the greenhouse represent a worst-case scenario; warm soil temperature, low soil $\mathrm{pH}$, high inoculumn level next to emerging roots, a diversity of isolates from five farms, and ample moisture (Gossen et al., 2014). Despite conditions being ideal for disease development, most resistant cultivars had a low frequency of clubbing in the greenhouse than in the laboratory. The difference in CI and DSI between the field trials and the greenhouse suggest that field screening is a better method for evaluating clubroot resistance because of the greater diversity of virulent pathotypes in a field. However, finding a field site with uniform disease pressure, or environmental conditions conducive to clubbing can be a challenge. For example, trials were initiated on five farms in fields with a history of clubroot, and although clubroot was present in all fields, disease incidence and severity were only uniformly distributed across two field sites. For efficiency, preliminary resistance screening should be initiated in the greenhouse to identify resistant cultivars, followed by evaluation of these cultivars in infested fields to better assess resistance potential.

All the resistant cultivars evaluated from $B$. oleracea showed high resistance to pathotype 16/02/30 except for kohlrabi (Table 4). Cabbage cultivars Tekila and Kilaton, and

Table 3. Reaction of European clubroot differential (ECD) set hosts to collections of clubroot from western Oregon.

\begin{tabular}{|c|c|c|c|c|c|c|c|c|c|c|c|c|c|c|c|c|c|}
\hline \multirow{3}{*}{$\begin{array}{l}\text { Collection } \\
\text { location }\end{array}$} & \multirow[b]{3}{*}{ Host crop } & \multicolumn{15}{|c|}{ Disease reaction $^{\mathrm{z}}$} & \multirow{3}{*}{$\begin{array}{c}\text { Pathotype } \\
\text { numerical } \\
\text { designation } \\
\end{array}$} \\
\hline & & \multicolumn{5}{|c|}{ Brassica campestris } & \multicolumn{5}{|c|}{ Brassica napus } & \multicolumn{5}{|c|}{ Brassica olevacea } & \\
\hline & & 01 & 02 & 03 & 04 & 05 & 06 & 07 & 08 & 09 & 10 & 11 & 12 & 13 & 14 & 15 & \\
\hline 2. St. Paul & Cabbage & - & - & - & - & + & ? & + & - & - & - & $?$ & + & + & + & + & $16 / 2 / 30$ \\
\hline 3. Sauvie Island ${ }^{x}$ & Broccoli & - & - & - & - & + & $?$ & + & - & $?$ & - & - & + & + & + & + & $16 / 2 / 30$ \\
\hline 4. Damascus & Cabbage & - & - & - & - & + & $?$ & + & - & - & - & - & + & + & + & + & $16 / 2 / 30$ \\
\hline Corvallis ${ }^{w}$ & Broccoli & - & - & - & - & + & $?$ & + & - & - & $?$ & + & + & + & + & + & $16 / 2 / 31$ \\
\hline Brooks $^{\mathrm{w}}$ & Cauliflower & - & - & $?$ & - & + & + & + & $?$ & - & $?$ & + & + & + & + & + & $16 / 3 / 31$ \\
\hline
\end{tabular}

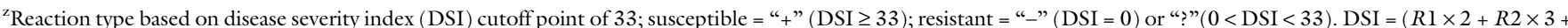
$R 3 \times 5) \div 5$, where $R 1, R 2$, and $R 3$ are the percentages of total plants evaluated with a rating of 1 (small clubs on lateral roots), 2 ( $<50 \%$ of main root system clubbed), and 3 $(>50 \%$ of main root system clubbed), respectively.

"Each positive ("+") ECD host of each Brassica species group was assigned a corresponding binary value (Table 1 ), which were then added together to create the pathotype numerical designation. For example, a positive reaction for B. campestris host $5, B$. napus hosts $6,7,8,9$, and $B$. oleracea 13,14 would be designated $16 / 15 / 12$.

${ }^{x}$ This collection location was also the location of a field trial (Table 4).

wesults from Dobson et al. (1983) added for comparison. 
Table 4. Clubroot incidence (CI) and disease severity index (DSI) of brassica cultivars grown in commercial fields where clubroot was present or in the greenhouse with inoculated growing media.

\begin{tabular}{|c|c|c|c|c|c|}
\hline \multirow[b]{2}{*}{ Crop $^{y}$} & \multirow[b]{2}{*}{ Source ${ }^{\mathrm{x}}$} & \multirow[b]{2}{*}{ Cultivar } & \multicolumn{3}{|c|}{ CI $(\mathrm{DSI})^{\mathrm{z}}$} \\
\hline & & & Field site 1 & Field site 2 & Greenhouse \\
\hline $\operatorname{Broccoli}(S)$ & Sakata & Emerald Crown & $100 \mathrm{a}(77 \mathrm{a})^{\mathrm{w}}$ & - & $90(90)$ \\
\hline Brussels sprouts $(S)$ & Bejo & Diablo & - & - & $100(100)$ \\
\hline Brussels sprouts (R) & Syngenta & Crispus & - & - & $0(0)$ \\
\hline Cauliflower $(S)$ & Harris Moran & Artica & - & - & $100(100)$ \\
\hline Kohlrabi (S) & unknown & Kossack & $96 \mathrm{ab}(69)$ & - & $82(51)$ \\
\hline Kohlrabi (R) & Rijk Zwaan & Lech & 100 a $(69)$ & - & $100(88)$ \\
\hline Kohlrabi (R) & Hild & Azur Star & $77 \mathrm{~b}(5 \mathrm{l})$ & - & $67(37)$ \\
\hline Napa Cabbage (S) & unknown & Michihili & 88 a $(80 a)$ & - & $100(100)$ \\
\hline Napa Cabbage (R) & Bejo & Emiko & - & - & $0(0)$ \\
\hline Napa Cabbage (R) & Bejo & Bilko & $10 \mathrm{~b}(6 \mathrm{~b})$ & - & $0(0)$ \\
\hline Napa Cabbage (R) & Seed Science & Panda & - & - & $0(0)$ \\
\hline Napa Cabbage (R) & Asia Seed & Chun Dae Gil & - & - & $60(60)$ \\
\hline $\operatorname{Pak}$ choi $(S)$ & Sakata & Joi Choi & $100(88)$ & - & $90(86)$ \\
\hline Pak choi (R) & Sakata & Feng Qing Choi & $98(90)$ & - & $100(100)$ \\
\hline Pak choi (R) & Sakata & Mei Quing Choi & - & - & $74(74)$ \\
\hline Turnip $(S)$ & Takii & Purple Prince & $9 \mathrm{~b}(5 \mathrm{~b})$ & - & $0(0)$ \\
\hline Turnip (R) & Kobayashi & Scarlet Queen & $98 \mathrm{a}(89 \mathrm{a})$ & - & 82 \\
\hline Cabbage (S) & Bejo & Farao & 100 a (87 a $)$ & - & $100(100)$ \\
\hline Cabbage (S) & Bejo & Gazelle & - & $100 \pm 0(84 \pm 5)^{\mathrm{v}}$ & - \\
\hline Cabbage (R) & Syngenta & Kilaton & $3 b(3 b)$ & $5 \pm 5(2 \pm 2)$ & $0(0)$ \\
\hline Cabbage (R) & Syngenta & Tekila & - & $0 \pm 0(0 \pm 0)$ & $0(0)$ \\
\hline Cabbage (R) & Syngenta & Kilagreg & $5 \mathrm{~b}(4 \mathrm{~b})$ & $5 \pm 5(5 \pm 5)$ & $0(0)$ \\
\hline
\end{tabular}

${ }^{\mathrm{z}} \mathrm{CI}=$ percentage of total plants evaluated with visible clubbing; DSI $=(R 1 \times 2+R 2 \times 3+R 3 \times 5) \div 5$, where $R 1, R 2$, and $R 3$ are the percentages of total plants evaluated with a rating of 1 (small clubs on lateral roots), 2 ( $<50 \%$ of main root system clubbed), and 3 ( $>50 \%$ of main root system clubbed), respectively.

${ }^{y_{S}}=$ susceptible control; $\mathrm{R}=$ cultivar with purported resistance to clubroot.

xAsia Seed (Asia Seed Co., Seoul, South Korea), Bejo (Bejo Seeds, Oceano, CA), Harris Moran (Harris Moran Seed Co., Modesto, CA), Hild (Hild Samen, Marbach, Germany), Kobayashi (Kobayashi Seed Co., Kakogawa, Japan), Rijk Zwaan (De Lier, The Netherlands), Sakata (Sakata Seed America, Morgan Hill, CA), Seed Science (Salinas, CA), Syngenta (Syngenta Seeds, Minneapolis, MN), Takii (Takii Seed, Kyoto, Japan), Tozer (Tozer Seeds, Cobham, United Kingdom).

wMeans within a column for a crop followed by the same letter are not statistically different based on Tukey's test at $P \leq 0.05$. If no letter present, there was no statistical difference (ANOVA at $P<0.05$ ).

${ }^{\mathrm{v}}$ Mean \pm SE $(n=5$ subsamples, each consisting of five plants per subsample); the experimental design was unreplicated, and ANOVA could not be applied.

brussels sprouts cultivar Crispus have demonstrated resistance to pathotype $6(16 / 00 / 14)$ in Canadian field trials (Saude et al., 2012; Sharma et al., 2013). The following cultivars showed high resistance in our study: Clapton and Clarify cauliflower, Lodero red cabbage, Kilagreg green cabbage, and Emerald Jewel broccoli. Purple kohlrabi cultivar Azur Star showed low resistance (CI 77\%) compared with the susceptible control (CI 96\%). This level of resistance would likely be unacceptable to farmers, and growing these cultivars would not contribute to a significant reduction in soil spore concentrations.

Napa cabbages displayed high levels of resistance to clubroot. The cultivars Bilko, Yuki, China Gold, and Emiko have previously shown high resistance to pathotype $6(16 / 00 / 14)$ in Canadian trials (Adhikari et al., 2012; Saude et al., 2012; Sharma et al., 2013). 'Panda', was the only napa cabbage with low resistance in this study, with $60 \%$ disease incidence and the highest disease rating $(R 3)$ for every infected plant. By comparison, the susceptible control had $100 \%$ incidence (Table 4).

No resistance was observed for the pak choi cultivars Feng Quing Choi and Mei Quing Choi. 'Feng Quing Choi' has not shown resistance to pathotype 6 (16/00/14; Adhikari et al., 2012) and 'Mei Quing Choi' has not shown resistance to pathotypes $6(16 / 00 / 14)$ and $3(16 / 15 / 12$; Sharma et al., 2013).

Clubroot incidence was the most variable for rutabaga of all the crops evaluated at field site 1. For example, the range in CI for 'American Purple Top' was $0 \%$ to $78 \%$. In the field, average CI was $32 \%$ and $26 \%$ for 'American Purple Top' and 'Marian', respectively, but in the greenhouse, no clubbing was observed. This is surprising given that the spore suspension used in greenhouse trials contained clubs all sites including from field site 1 where clubbing was observed.

Brassica species vary in their genetic resistance to clubroot. Dominant, pathotype-specific resistance has been 
found in B. rapa and B. napus, and predominantly recessive, pathotypenonspecific resistance has been found in B. oleracea. Some attempts to deploy resistance found in B. oleracea resulted in resistance being overcome by more virulent races (J.R. Baggett, personal communication; Diederichsen et al., 2009). In addition, seed companies do not breed for recessive forms of resistance because they require that resistance alleles be present in both inbred parents used for $\mathrm{F}_{1}$ hybrid production: $F_{1}$ hybrids are the principal cultivar type used with the vegetable Brassica species. The dominant forms of resistance from B. napus and B. rapa have been transferred via interspecific hybridization and embryo rescue into B. oleracea in part because resistant $F_{1}$ hybrids result from only one inbred parent having dominant resistance. Dominant resistance is most likely the form present in the brassica cultivars evaluated in this study.

To preserve genetic resistance, planting resistant cultivars must be part of an integrated clubroot management strategy, rather than the only strategy. Diversity of virulent phenotypes exists within field populations (Jones et al., 1982; Xue et al., 2008) and some of these may be present only at low frequencies. Reliance on resistant cultivars in a short rotation may result in the selection of pathotypes capable of overcoming resistance. For example, frequent planting of resistant canola cultivars has led to the erosion of resistance in Canada (LeBoldus et al., 2012; Strelkov et al., 2016).

This study demonstrates the role of resistant vegetable cultivars in managing clubroot. Farmers who grow resistant cultivars can minimize inseason crop loss, and perhaps reduce future disease incidence and severity by reducing the quantity of spores being added to a field. However, as a management strategy, growing resistant cultivars has its limitations. For some high-demand crops such as kale (B. oleracea var. acephala), mustard greens (Brassica juncea), and arugula (Eruca sativa), no resistant cultivars are available. Even when available, the selection of commercially available resistant cultivars is limited, and these resistant cultivars may not meet farmer, industry, or consumer requirements. To minimize the potential for selection of a virulent population that overcomes resistance, using clubrootresistant cultivars must be part of an integrated clubroot management program that includes long rotations out of brassica crops and cultural strategies such as $\mathrm{pH}$ management.

\section{Literature cited}

Adhikari, K.K.C., B.D. Gossen, and M.R. McDonald. 2012. Reaction to Plasmodiophora brassicae pathotype 6 in lines of brassica vegetables, Wisconsin Fast Plants, and canola. HortScience 47:374-377.

Buczacki, S.T., H. Toxopeus, P. Mattusch, T. Johnston, G. Dixon, and L. Hobolth. 1975. Study of physiologic specialization in Plasmodiophora brassicae: Proposals for attempted rationalization through an international approach. Trans. Br. Mycol. Soc. 65:295-303.

Crute, I., A. Gray, P. Crisp, and S. Buczacki. 1980. Variations in Plasmodiophora brassicae and resistance to clubroot disease in brassicas and allied crops - A critical review. Plant Breeding Abstr. 50:91-104.

Diederichsen, E., M. Frauen, E.G.A. Linders, K. Hatakeyema, and M. Hirai. 2009. Status and perspectives of clubroot resistance breeding in crucifer crops. J. Plant Growth Regul. 28:265-281.

Dixon, G.R. 2006. The biology of Plasmodiophora brassicae Wor. A review of recent advances. Acta Hort. 706:271282.

Dixon, G.R. 2009. The occurrence and economic impact of Plasmodiophora brassicae and clubroot disease. J. Plant Growth Regul. 28:194-202.

Dixon, G.R. and D.L. Robinson. 1986. The susceptibility of Brassica oleracea cultivars to Plasmodiophora brassicae (clubroot). Plant Pathol. 35:101-107.

Dobson, R.L., J. Robak, and R. Gabrielson. 1983. Pathotypes of Plasmodiophora brassicae in Washington, Oregon, and California. Plant Dis. 67:269-271.

Donald, E.C. and I. Porter. 2009. Integrated control of clubroot. J. Plant Growth Regul. 28:289-303.

Gossen, B.D., A. Deora, G. Peng, S. Hwang, and M. McDonald. 2014. Effect of environmental parameters on clubroot development and the risk of pathogen spread. Can. J. Plant Pathol. 36:37-48.

Hwang, S.F., H.U. Ahmed, S.E. Strelkov, B.D. Gossen, G.D. Turnbull, G. Peng, and R.J. Howard. 2011. Seedling age and inoculum density affect clubroot severity and seed yield in canola. Can. J. Plant Sci. 91:183-190.
Hwang, S.F., H.U. Ahmed, Q. Zhou, A. Rashid, S.E. Strelkov, B.D. Gossen, G. Peng, and G.D. Turnbull. 2012. Assessment of the impact of resistant and susceptible canola on Plasmodiophora brassicae inoculum potential. Plant Pathol. 61:945952.

Hwang, S.F., R.J. Howard, S.E. Strelkov, B.D. Gossen, and G. Peng. 2014. Management of clubroot (Plasmodiophora brassicae) on canola (Brassica napus) in western Canada. Can. J. Plant Pathol. 36:49-65.

Jones, D.R., D.S. Ingram, and G.R. Dixon. 1982. Characterization of isolates derived from single resting spores of Plasmodiophora brassicae and studies of their interaction. Plant Pathol. 31:239246.

Kuginuki, Y., H. Yoshikawa, and M. Hirai. 1999. Variation in virulence of Plasmodiophora brassicae in Japan tested with clubroot resistant cultivars of Chinese cabbage (Brassica rapa L. spp. pekinensis)Eur. J. Plant Pathol.105327332.

LeBoldus, J.M., V.P. Manolii, T.K. Turkington, and S.E. Strelkov. 2012. Adaptation to brassica host genotypes by a single- spore isolate and population of Plasmodiophora brassicae (clubroot). Plant Dis. 96:833-838.

Peng, G., D. Pageau, S.E. Strelkov, B.D. Gossen, S.F. Hwang, and R. Lahlali. 2015. A $>2$-year crop rotation reduces resting spores of Plasmodiophora brassicae in soil and the impact of clubroot on canola. Eur. J. Agron. 70:78-84.

Piao, Z., N. Ramchiary, and Y.P. Lim. 2009. Genetics of clubroot resistance in brassica species. J. Plant Growth Regul. 28:252-264.

Saude, C., A. Mckeown, B.D. Gossen, and M.R. McDonald. 2012. Effect of host resistance and fungicide application on clubroot pathotype 6 in green cabbage and napa cabbage. HortTechnology 22:311-319.

Sharma, K., B.D. Gossen, R. Howard, T. Gludovacz, and M.R. McDonald. 2013. Reaction of selected brassica vegetable crops to Canadian pathotypes of Plasmodiophora brassicae. Can. J. Plant Pathol. 35:371-383.

Strelkov, S.E., S.F. Hwang, V.P. Manolii, T. Cao, and D. Feindel. 2016. Emergence of new virulence phenotypes of Plasmodiophora brassicae on canola (Brassica napus) in Alberta, Canada. Eur. J. Plant Pathol. 145:517-529.

Strelkov, S.E., J.P. Tewari, M. Hartman, and D. Orchard. 2005. Clubroot on canola in Alberta in 2003 and 2004. Can. Plant Dis. Surv. 85:72-73. 


\section{Research Reports}

Strelkov, S.E., J.P. Tewari, and E. SmithDegenhardt. 2006. Characterization of Plasmodiophora brassicae populations from Alberta, Canada. Can. J. Plant Pathol. 28:467-474.

Tsushima, A., H. Murakami, T. Akimoto, M. Katahira, Y. Kuroyanagi, and Y. Shishido. 2010. A practical estimating method of the dose-response curve between inoculum density of Plasmodiophora brassicae and the disease severity for long-term IPM strategiesJpn. Agr. Res. Qrtly. 44383390.

Wallenhammar, A.C. 1996. Prevalence of Plasmodiophora brassicae in a spring oilseed rape growing area in central Sweden and factors influencing soil infestation levels. Plant Pathol. 45:710-719.

Williams, P.H. 1966. A system for the determination of races of Plasmodiophora brassicae that infect cabbage and rutabaga. Phytopathology 56:624-626.

Wit, F. 1964. Inheritance of reaction to clubroot in turnips. Hort. Res. 5:47-49.

Xue, S., T. Cao, R.J. Howard, S.F. Hwang, and S.E. Strelkov. 2008. Isolation and variation in virulence of singlespore isolates of Plasmodiophora brassicae from Canada. Plant Dis. 92:456-462. 